Pacific Journal of Mathematic 


\title{
A SUM OF A CERTAIN DIVISOR FUNCTION FOR ARITHMETICAL SEMI-GROUPS
}

\author{
E. M. HORADAM
}

Let $\left\{b_{n}\right\}$ denote the set of elements of a free ordered arithmetical semi-group with multiplication and a known counting function. Using the corresponding terminology of arithmetic let $b_{n}=d \delta$ and let $\tau^{\prime}\left(b_{n}\right)$ denote the number of divisors $d$ of $b_{n}$ where both $d$ are $\delta$ and square free. Then it is shown here that $T(x)$ defined by

$$
T(x)=\sum_{\substack{b, \leq x \\\left(b_{n}, b_{u}\right)=1}} \tau^{\prime}\left(b_{n}\right) \sim A x \log x
$$

where $A$ is a constant depending on $b_{u}$.

A more explicit definition of the semi-group is as follows. Suppose there is an infinite sequence $\{p\}$ of real numbers, which we will call generalised primes, such that

$$
1<p_{1}<p_{2}<\cdots .
$$

Form the set $\{b\}$ of all $p$-products, i.e., products $p_{1}^{v_{1}} p_{2}^{v_{2}} \cdots$, where $v_{1}, v_{2}, \cdots$ are integers $\geqq 0$ of which all but a finite number are 0 . Call these numbers generalised integers and suppose that no two generalised integers are equal if their $v^{\prime}$ s are different. Then assume $\{b\}$ may be arranged as an increasing sequence:

$$
1=b_{1}<b_{2}<\cdots<b_{n}<\cdots .
$$

We say $d \mid b_{n}$ if $d \in\{b\}$ and there exists $\delta \in\{b\}$ such that $d \delta=b_{n} ; d$ and $\delta$ are then called complementary divisors of $b_{n}$. Let $\tau^{\prime}\left(b_{n}\right)$ be the number of divisors $d$ of $b_{n}$ where both $d$ and its complementary divisor are square free. In fact

$$
\begin{gathered}
\tau^{\prime}\left(b_{n}\right)=\sum_{d \delta=b_{n}} 1 . \\
d \text { square free } \\
\delta \text { square free }
\end{gathered}
$$

This means that $\tau^{\prime}\left(b_{n}\right)=0$ unless $b_{n}$ is of the form $\prod_{i j} p_{i} p_{j}^{2}$. Let $x$ be any positive number and $b_{u}$ any generalised integer. The sum to be evaluated, $T(x)$ is defined by

$$
T(x)=\sum_{\substack{b_{n} \leq x \\\left(b_{n}, b_{u}\right)=1}} \tau^{\prime}\left(b_{n}\right)
$$

where $\left(b_{n}, b_{u}\right)$ denotes the greatest common divisor of $b_{n}$ and $b_{u}$. In 
order to evaluate this sum a further assumption on the number of generalised integers less than or equal to $x$ is required. Let $[x]$ denote the number of generalised integers $\leqq x$.

Assume

$$
[x]=x+R(x), R(x)=0\left(x^{\alpha}\right) \text { and } 0<\alpha<1 .
$$

Using (1.3) it will be shown that when $b_{u}$ is square free

$$
T(x)=A x \log x+0\left(x \exp \cdot\left\{\frac{\left(\log b_{u}\right)^{1-\alpha}}{\log \log b_{u}}\right\}\right)
$$

where

$$
A=\prod_{p \mid b_{u} u} \frac{p^{2}}{(p+1)^{2}} \prod_{p} \frac{\left(p^{2}-1\right)^{2}}{p^{4}} .
$$

This sum is similar to that found by Gordon and Rogers in [2]. Also using the methods of [2] exactly analagous results for arithmetical semi-groups can be found to those shown by Gordon and Rogers. The only extra difficult result required is the prime number theorem for generalised integers. This is proved in [6] and is

$$
\pi(x)=\frac{x}{\log x}+0\left(\frac{x}{\log ^{2} x}\right) .
$$

2. Supplementary definitions and results. Define the Möbius function $\mu\left(b_{n}\right)$ for the semi-group as follows: $\mu\left(b_{n}\right)=0$ if $b_{n}$ has a square factor $\mu\left(b_{n}\right)=(-1)^{k}$, where $k$ denotes the number of prime divisors of $b_{n}$ and $b_{n}$ has no square factor; $\mu(1)=1$. Let $\phi\left(x, b_{u}\right)$ denote the number of generalised integers $\leqq x$ which are prime to $b_{u}$. Then it is proved in [3] that

$$
\sum_{d \mid b_{n}} \mu(d)=\left\{\begin{array}{l}
0 \text { when } b_{n} \neq 1 \\
1 \text { when } b_{n}=1
\end{array}\right.
$$

and in [4] that

$$
\phi\left(x, b_{u}\right)=\sum_{d \backslash b_{u}} \mu(d)\left[\frac{x}{d}\right]
$$

Hence using assumption (1.3) we have

$$
\begin{aligned}
\dot{\phi}\left(x, b_{u}\right) & =x \sum_{d \mid b_{u}} \frac{\mu(d)}{d}+0\left(x^{\alpha} \sum_{d \mid b_{u}} \frac{|\mu(d)|}{d^{\alpha}}\right) . \\
& =x f\left(b_{u}\right)+0\left(x^{\alpha} f_{\alpha}\left(b_{u}\right)\right) \text { say } .
\end{aligned}
$$

Then as is shown in [3], and in any case as the functions are multiplicative 


$$
\begin{gathered}
f\left(b_{u}\right)=\sum_{d \mid b_{u}} \frac{\mu(d)}{d}=\prod_{p \mid b_{u}}\left(1-\frac{1}{p}\right), \\
f_{\alpha}\left(b_{u}\right)=\sum_{d \mid b_{u}} \frac{|\mu(d)|}{d^{\alpha}}=\prod_{p \mid b_{u}}\left(1+\frac{1}{p^{\alpha}}\right) .
\end{gathered}
$$

Define $\zeta(s)=\sum_{n=1}^{\infty} b_{n}^{-s}(s>1)$. Then it is proved in [1], using an assumption equivalent to (1.3) that

$$
\zeta(s)=\prod_{r=1}^{\infty}\left(1-p_{r}^{-s}\right)^{-1} .
$$

Hence

$$
\frac{1}{\zeta(s)}=\prod_{r=1}^{\infty}\left(1-p_{r}^{-s}\right)=\sum_{n=1}^{\infty} \mu_{n} b_{n}^{-s} .
$$

Abel's transformation, in the following form, will be used to give some necessary estimates. Suppose $\left\{b_{n}\right\}$ and $\left\{a_{n}\right\}$ are given with $b_{1} \leqq b_{2} \leqq \cdots, b_{n} \rightarrow \infty$. Let $A(x)=\sum_{b_{n} \leqq x} a_{n}$. Suppose $\psi(x)$ has a continuous derivative $\psi^{\prime}(x)$ for all $x$ involved. Then

$$
\sum_{b_{n} \leqq x} a_{n} \psi\left(b_{n}\right)=A(x) \psi(x)-\int_{b_{1}}^{x} A(u) \psi^{\prime}(u) d u .
$$

Using (1.3) and this transformation, we obtain the following results.

$$
\sum_{b_{n} \leqq x} \frac{1}{b_{n}^{\beta}}=\frac{x^{1-b}}{1-\beta}+\gamma_{\beta}+0\left(x^{\alpha-\beta}\right),\left\{\begin{array}{l}
\beta \neq 1 \\
\beta \neq \alpha,
\end{array}\right.
$$

and $\gamma_{\beta}$ is a constant equal to $\zeta(\beta)$ when $\beta>1$.

$$
\begin{gathered}
\sum_{b_{n} \leqq x} \frac{1}{b_{n}^{\alpha}}=\frac{x^{1-\alpha}}{1-\alpha}+0(\log x) . \\
\sum_{b_{n}>x} \frac{1}{b_{n}^{\beta}}=\zeta(\beta)-\sum_{b_{n} \leqq x} \frac{1}{b_{n}^{\beta}}=0\left(x^{1-\beta}\right) \text { for } \beta>1 .
\end{gathered}
$$

Again using (1.5) and Abel's transformation we obtain$$
\sum_{p \leqq x} \frac{1}{p^{\alpha}}=\frac{x^{1-\alpha}}{(1-\alpha) \log x}+0\left(\frac{x^{1-\alpha}}{\log ^{2} x}\right)
$$$$
\sum_{p \leqq x} \log p=x+0(x / \log x) .
$$

Define

$$
\lambda\left(b_{u}\right)=\sum_{\substack{b_{n}=1 \\\left(b_{n}, b_{u}\right)=1}}^{\infty} \frac{\mu\left(b_{n}\right)}{b_{n}^{2}}=\prod_{\substack{p \\ p / b_{u}}}\left(1-\frac{1}{p^{2}}\right) .
$$

Then from (2.7) we have 


$$
\sum_{\substack{b_{n} \leq x \\\left(b_{n}, b_{u}\right)=1}} \frac{\mu\left(b_{n}\right)}{b_{n}^{2}}=\lambda\left(b_{u}\right)+0\left(x^{-1}\right) .
$$

\section{The $Q$ function. Let}

$$
\begin{aligned}
q_{u}\left(b_{n}\right) & =\left\{\begin{array}{l}
1 \text { if } b_{n} \text { is square free and }\left(b_{n}, b_{u}\right)=1 \\
0 \text { otherwise } .
\end{array}\right. \\
Q_{u}(x) & =\sum_{b_{n} \leqq x} q_{u}\left(b_{n}\right) . \\
e\left(b_{n}\right) & = \begin{cases}1 & \text { if } b_{n}=1 \\
0 & \text { if } b_{n} \neq 1\end{cases}
\end{aligned}
$$

Then from (2.1)

$$
q_{u}\left(b_{n}\right)=e\left(\left(b_{n}, b_{u}\right)\right) \sum_{d^{2} \delta=b_{n}} \mu(d)
$$

This gives

$$
\begin{aligned}
& Q_{u}(x)=\sum_{b_{n} \leqq x} e\left(\left(b_{n}, b_{u}\right)\right) \sum_{d^{2} \delta=b_{n}} \mu(d) \\
& =\sum_{\substack{d^{2} \delta \leq x \\
\left(d, b_{u}\right)=\left\{\delta, b_{u}\right)=1}} \mu(d) \\
& =\sum_{\substack{d \leq \downarrow \sqrt{x} \\
(d, \bar{b} u=1}} \mu(d) \dot{\phi}\left(\frac{x}{d^{2}}, b_{u}\right) \\
& =\sum_{\substack{d \leq \downarrow \leq x \\
\left(d, b_{u}\right)=1}} \mu(d)\left\{\frac{x}{d^{2}} f\left(b_{u}\right)+0\left(\frac{x^{\alpha}}{d^{2 \alpha}} f\left(b_{u}\right)\right)\right\}
\end{aligned}
$$

from $(2.3)$

$$
=x f\left(b_{u}\right)\left\{\lambda\left(b_{u}\right)+0\left(x^{-1 / 2}\right)\right\}+0\left(x^{\alpha} f_{\alpha}\left(b_{u}\right)\left\{\frac{x^{(1-2 \alpha) / 2}}{1-2 \alpha}+\gamma_{2 \alpha}\right\}\right)
$$

from (2.11) and (2.5). Hence

$$
Q_{u}(x)=x f\left(b_{u}\right) \lambda\left(b_{u}\right)+0\left(x^{1 / 2} f_{\alpha}\left(b_{u}\right)\right)+0\left(x^{\alpha} f_{\alpha}\left(b_{u}\right)\right) .
$$

4. The evaluation of the sum of the divisor function $T(x)$. Replacing in (1.2) the value for $\tau^{\prime}\left(b_{n}\right)$ defined in $(1.1)$, we have the result that $T(x)$ is the number of elements in the class satisfying $d \delta=b_{n}, \mu^{2}(d)=\mu^{2}(\delta)=1$, where $b_{n} \leqq x,\left(b_{n}, b_{u}\right)=1$. This is the same class as that for which $d \delta \leqq \hat{\alpha},\left(d, b_{u}\right)=\left(\delta, b_{u}\right)=1$ and $\mu^{2}(d)=\mu^{2}(\delta)=1$. Rearranging the order of summation we have that $T(x)$ is the number of elements in the class satisfying $\delta \leqq x / d,\left(\delta, b_{u}\right)=1, \delta$ square free, where $d \leqq x,\left(d, b_{u}\right)=1$ and $d$ is square free. Hence 


$$
\begin{aligned}
T(x) & =\sum_{d \leqq x} q_{u}(d) \sum_{\delta \leqq x / d} q_{u}(\delta) \\
& =\sum_{d \leqq x} q_{u}(d)\left\{\frac{x}{d} f\left(b_{u}\right) \lambda\left(b_{u}\right)+0\left(\frac{x^{1 / 2}}{d^{1 / 2}} f_{\alpha}\left(b_{u}\right)\right)+0\left(\frac{x^{\alpha}}{d^{\alpha}} f_{\alpha}\left(b_{u}\right)\right)\right\}
\end{aligned}
$$

from (3.1)

$$
\begin{aligned}
&=x f\left(b_{u}\right) \lambda\left(b_{u}\right) \sum_{d \leqq x} \frac{q_{u}(d)}{d}+0\left(x^{1 / 2} f_{\alpha}\left(b_{u}\right) \sum_{d \leqq x} \frac{1}{d^{1 / 2}}\right) \\
&+0\left(x^{\alpha} f_{\alpha}\left(b_{u}\right) \sum_{d \leqq x} \frac{1}{d^{\alpha}}\right) \\
&=x f\left(b_{u}\right) \lambda\left(b_{u}\right) \sum_{d \leqq x} \frac{q_{u}(d)}{d}+0\left(x f_{\alpha}\left(b_{u}\right)\right)
\end{aligned}
$$

from (2.5) and (2.6).

Now from (3.1) and Abel's transformation we have

$$
\begin{aligned}
\sum_{d \leqq x} \frac{q_{u}(d)}{d}= & f\left(b_{u}\right) \lambda\left(b_{u}\right) \log x+0\left(f_{\alpha}\left(b_{u}\right)\right) \\
& +0\left(x^{-1 / 2} f_{\alpha}\left(b_{u}\right)\right)+0\left(x^{\alpha-1} f_{\alpha}\left(b_{u}\right)\right) .
\end{aligned}
$$

Substituting this result in the expression for $T(x)$ we obtain

$$
T(x)=f^{2}\left(b_{u}\right) \lambda^{2}\left(b_{u}\right) x \log x+0\left(x f_{\alpha}\left(b_{u}\right)\right) .
$$

From the definition in (2.4) we have

$$
f_{\alpha}\left(b_{u}\right)=\sum_{d \mid b_{u}} \frac{|\mu(d)|}{d^{\alpha}} \leqq \sum_{d \mid b_{u}} \frac{1}{d^{\alpha}} \leqq \sum_{d \mid b_{u}} 1=0\left(b_{u}^{\delta}\right)
$$

where $\delta$ is any positive real number. This is proved in [5, Th. 5] and is true for all $b_{u}$. However, when $b_{u}$ is square free we can obtain a better value for $f_{\alpha}\left(b_{u}\right)$ by using the prime number theorem. Suppose $b_{u}$ is square free and let $b_{u}=p_{u 1} p_{u 2} \cdots p_{u k} \geqq p_{1} p_{2} \cdots p_{k}$. Then

$$
\log b_{u} \geqq \sum_{p \leqq p_{k}} \log p=p_{k}+0\left(p_{k} / \log p_{k}\right)
$$

from (2.9). Hence

$$
\begin{aligned}
f_{\alpha}\left(b_{u}\right) & =\sum_{d \mid b_{u}} \frac{|\mu(d)|}{d^{\alpha}}=\prod_{p \mid b_{u}}\left(1+\frac{1}{p^{\alpha}}\right) \leqq \prod_{p \leqq p_{k}}\left(1+\frac{1}{p^{\alpha}}\right) \\
& \leqq \prod_{p \leqq(1+o(1)) \log _{u} b_{u}}\left(1+\frac{1}{p^{\alpha}}\right)
\end{aligned}
$$

from (4.3), and so

$$
\log f_{\alpha}\left(b_{u}\right) \leqq \sum_{p \leqq(1+o(1)) \log b_{u}} \frac{1}{p^{\alpha}}(1+o(1)) .
$$

Then from (2.8) 


$$
f_{\alpha}\left(b_{u}\right)=0\left(\exp \cdot\left\{\frac{\left(\log b_{u}\right)^{1-\alpha}}{\log \log b_{u}}\right\}\right)
$$

for $b_{u}$ square free. Now from (2.4) and (2.10)

$$
\begin{aligned}
f^{2}\left(b_{u}\right) \lambda^{2}\left(b_{u}\right) & =\prod_{p \nmid b_{u}}\left(1-\frac{1}{p}\right)^{2} \prod_{\substack{p \\
p / b_{u}}}\left(1-\frac{1}{p^{2}}\right)^{2} \\
& =\prod_{p \nmid b_{u}} \frac{p^{2}}{(p+1)^{2}} \prod_{p} \frac{\left(p^{2}-1\right)^{2}}{p^{4}} \\
& =A \text { (say). }
\end{aligned}
$$

Hence from (4.1), (4.2) and (4.4) we have

$$
T(x)=A x \log x+0\left(x b_{u}^{\delta}\right)
$$

for all $b_{u}$ and all positive real numbers $\delta$ and

$$
T(x)=A x \log x+0\left(x \exp \left\{\frac{\left(\log b_{u}\right)^{1-\alpha}}{\log \log b_{u}}\right\}\right)
$$

for all square free $b_{u}$.

This is the result given for $T(x)$ in (1.4). Since

$$
\prod_{p}\left(1-\frac{1}{p^{2}}\right)^{2}=\frac{1}{\zeta^{2}(2)},
$$

the value for $A$ may also be written

$$
A=\frac{1}{\zeta^{2}(2)} \prod_{p \mid b_{u}} \frac{p^{2}}{(p+1)^{2}} .
$$

I gratefully acknowledge assistance given by the referee in the evaluation of the error term.

\section{REFERENCES}

1. A. Beurling, Analyse de la loi asymptotique de la distribution des nombres premiers généralisés, Acta. Math. 68 (1937), 255-291.

2. G. Gordon and K. Rogers, Sums of the divisor function, Cana. J. Math. 16 (1964), 151-158.

3. E. M. Horadam, Arithmetical functions of generalised primes, Amer. Math. Monthly 68 (1961), 626-629.

4. - The number of unitary divisors of a generalised integer, Amer. Math. Monthly 71 (1964), 893-895.

5 . - The order of arithmetical functions of generalized integers, Amer. Math. Monthly 70 (1963), 506-512.

6. B. Nyman, A general prime number theorem, Acta. Math. 81 (1949), 299-307.

Received April 29, 1965.

UNIVERSity OF NeW ENGLAND

Armidale, N.S.W., Australia 


\section{PACIFIC JOURNAL OF MATHEMATICS}

\section{EDITORS}

\section{H. SAMELSON}

Stanford University

Stanford, California

J. P. JANS

University of Washington

Seattle, Washington 98105
J. DUGUNDJI

University of Southern California Los Angeles, California 90007

RICHARD ARENS

University of California

Los Angeles, California 90024

\section{ASSOCIATE EDITORS}
E. F. BECKENBACH
B. H. NEumanN
F. WOLF
K. YosidA

\section{SUPPORTING INSTITUTIONS}

\author{
UNIVERSITY OF BRITISH COLUMBIA \\ CALIFORNIA INSTITUTE OF TECHNOLOGY \\ UNIVERSITY OF CALIFORNIA \\ MONTANA STATE UNIVERSITY \\ UNIVERSITY OF NEVADA \\ NEW MEXICO STATE UNIVERSITY \\ OREGON STATE UNIVERSITY \\ UNIVERSITY OF OREGON \\ OSAKA UNIVERSITY \\ UNIVERSITY OF SOUTHERN CALIFORNIA
}

\author{
STANFORD UNIVERSITY \\ UNIVERSITY OF TOKYO \\ UNIVERSITY OF UTAH \\ WASHINGTON STATE UNIVERSITY \\ UNIVERSITY OF WASHINGTON \\ AMERICAN MATHEMATICAL SOCIETY \\ CHEVRON RESEARCH CORPORATION \\ TRW SYSTEMS \\ NAVAL ORDNANCE TEST STATION
}

Mathematical papers intended for publication in the Pacific Journal of Mathematics should be typewritten (double spaced). The first paragraph or two must be capable of being used separately as a synopsis of the entire paper. It should not contain references to the bibliography. Manuscripts may be sent to any one of the four editors. All other communications to the editors should be addressed to the managing editor, Richard Arens at the University of California, Los Angeles, California 90024.

50 reprints per author of each article are furnished free of charge; additional copies may be obtained at cost in multiples of 50 .

The Pacific Journal of Mathematics is published monthly. Effective with Volume 16 the price per volume ( 3 numbers) is $\$ 8.00$; single issues, $\$ 3.00$. Special price for current issues to individual faculty members of supporting institutions and to individual members of the American Mathematical Society: $\$ 4.00$ per volume; single issues $\$ 1.50$. Back numbers are available.

Subscriptions, orders for back numbers, and changes of address should be sent to Pacific Journal of Mathematics, 103 Highland Boulevard, Berkeley 8, California.

Printed at Kokusai Bunken Insatsusha (International Academic Printing Co., Ltd.), 7-17, Fujimi 2-chome, Chiyoda-ku, Tokyo, Japan.

PUBLISHED BY PACIFIC JOURNAL OF MATHEMATICS, A NON-PROFIT CORPORATION

The Supporting Institutions listed above contribute to the cost of publication of this Journal, but they are not owners or publishers and have no responsibility for its content or policies. 


\section{Pacific Journal of Mathematics

Vol. 22, No. $3 \quad$ March, 1967

Wai-Mee Ching and James Sai-Wing Wong, Multipliers and $H^{*}$

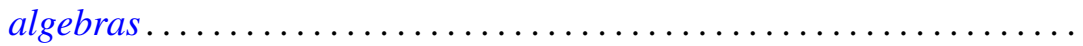

P. H. Doyle, III and John Gilbert Hocking, A generalization of the Wilder

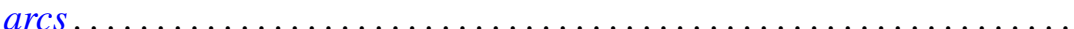

Irving Leonard Glicksberg, A Phragmén-Lindelöf theorem for function

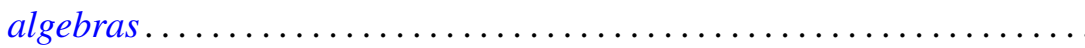

E. M. Horadam, A sum of a certain divisor function for arithmetical semi-groups ..................................... 407

V. Istrăţescu, On some hyponormal operators ................... 413

Harold H. Johnson, The non-invariance of hyperbolicity in partial

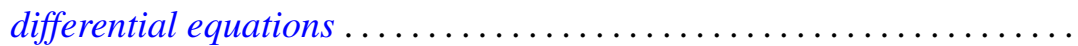

Daniel Paul Maki, On constructing distribution functions: A bounded denumerable spectrum with $n$ limit points................... 431

Ronald John Nunke, On the structure of Tor. II .................... 453

T. V. Panchapagesan, Unitary operators in Banach spaces ............. 465

Gerald H. Ryder, Boundary value problems for a class of nonlinear differential equations ................................. 477

Stephen Simons, The iterated limit condition and sequential convergence .................................... 505

Larry Eugene Snyder, Stolz angle convergence in metric spaces ......... 515 Sherman K. Stein, Factoring by subsets ................... 523

Ponnaluri Suryanarayana, The higher order differentiability of solutions of abstract evolution equations . . .

Leroy J. Warren and Henry Gilbert Bray, On the square-freeness of Fermat and Mersenne numbers ............................... 563

Tudor Zamfirescu, On l-simplicial convexity in vector spaces........... 565 Eduardo H. Zarantonello, The closure of the numerical range contains the spectrum 